\title{
academicjournals
}

Vol. 8(4), pp. 185-195, April 2014

DOI: 10.5897/AJ PS12.065

Artic le Number. B8A 79CE44200

ISSN 1996-0824

Copyright $\odot 2014$

African Journal of Plant Science

Author(s) reta in the copyright of this artic le

http://www.academic joumals.org/AJPS

\section{Extraction, characterization and application of natural dyes from selected plants in Uganda for dyeing of cotton fabrics}

\author{
P. A. G. Wanyama ${ }^{1 *}$, B. T. Kiremire ${ }^{2}$ and J. E. S. Murumu ${ }^{2}$ \\ ${ }^{1}$ Department of Chemistry, Kyambogo University, Kampala, P. O. Box 1, Uganda. \\ ${ }^{2}$ Department of Chemistry, Makerere University, Kampala, P. O Box 7062, Uganda.
}

Received 27 February, 2012; Accepted 2 April, 2014

\begin{abstract}
Cotton fabrics were dyed with natural dyes derived from the crude bark extracts of Albizia coriaria, Morinda lucida, Syzygium cordatum and Vitellaria paradoxa dye-yielding plants collected in 2004 from Mukono and Mbale districts of Uganda. Natural dyes are becoming very important in industry for their less toxic tendencies as compared to synthetic dyes. They are friendly to the environment and hence their increasing demand worldwide. Many new enterprises, of different sizes, have began to cultivate, extract and apply natural dyes. Dyeing was carried out using the simultaneous mordanting method with $10 \%$ (o.w.f) of four selected mordants. CIELab coordinates, Chroma (C) and Hue (H) values were found to be dependent on type of mordant and nature of the phenolic composition of the crude extracts. The colour fastness values, both to light and washing, were very good and of textile importance. The colour absorption values (K/S) were calculated using the Kubelka-Munk equation from reflectance values and the same varied from plant to plant due to differences in molecular structures and substantivity to the cotton fabrics. The mordanting process resulted into varied values of colour depth, chroma (C) and hues $(\mathrm{H})$ with significant changes in lightness values $(\mathrm{L})$, and mordant dependent. Colour fastness properties to light and washing were good, between 3 and 4 , suitable for textile application.
\end{abstract}

Key words: Extraction, characterization, natural dyes, selected plants, Uganda.

\section{INTRODUCTION}

Dye compounds from natural resources especially from plants are increasingly becoming important alternatives to synthetic dyes for use in the textile industry (Deo and Desai, 1999; Gokhale et al., 2004; Samanta and Agarwal,
2009). Unlike synthetic dyes which have been found to be toxic and harmful to the environment, natural dyes are biodegradable, non-toxic and generally have higher compatibility with the environment when compared with their

*Corresponding author. E-mail: aaronwanyama@gmail.com.

Author(s) agree that this article remain permanently open access under the terms of the Creative Commons Attribution License 4.0 International License 


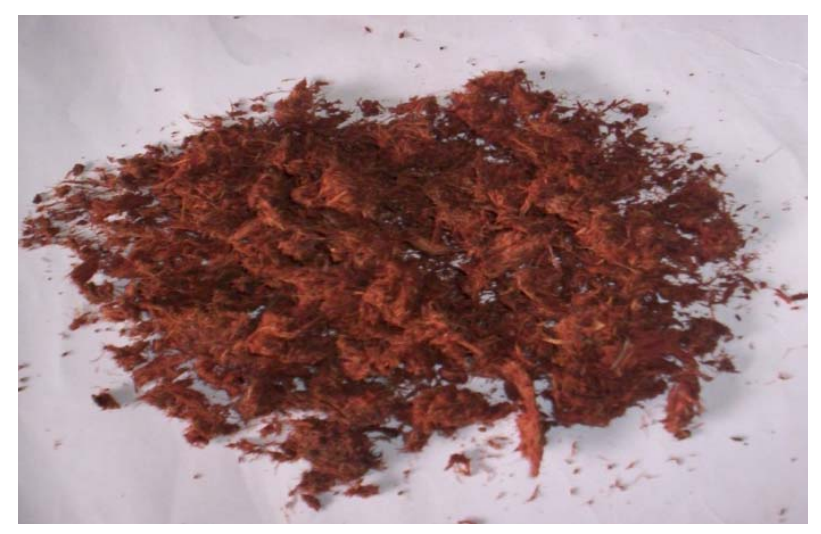

Figure 1. Albizia coriaria crude bark material.

synthetic counterparts (Maria et al., 2010). They can provide a wide range of beautiful shades with acceptable levels of colour fastness (Ekrami et al., 2011). Hence there is considerable research work being undertaken across the world on the application of natural dyes in the textile industry and the return to the use of natural dyes as important alternatives to synthetic dyes (Acguah and Oduro, 2012). Reports from India alone highlight an abundance of dye-yielding plants from whose different parts extraction of colour components for textile application and commercialization is gaining prominence in that part of the world (Mayunga, 2007).

Plants have had a long history of use on the African continent, inspiring enormous research efforts to prospect for lead natural products for drug and pesticide development, involving both local and foreign research groups (Mayunga, 2007). However, very little efforts in comparison have been reported in Africa in search for natural dye compounds for textile colouration. The African continent is rich in different plant species with potential to produce novel natural products with dye-yielding properties. Unfortunately, many of these plants remain unknown phytochemically, undocumented and lie in the wild unexploited and yet represent an enormous reservoir of new dye molecules awaiting discovery.

In this paper, extraction of dyes from Albizia coriaria, Morinda lucida, Vitellaria paradoxa and Syzygium cordatum selected dye-yielding plants in Uganda, dyeing of cotton fabrics with the extracted dyes and spectral characterization of the dyed fabrics are reported.

\section{MATERIALS AND METHODS}

Four potential dye-yielding plants namely; A. coriaria, M. lucida, V. paradoxa and S. cordatum were collected in 2004 from Mukono and Mbale districts of Uganda. The well ground crude dye powder of each plant was kept in a properly sealed and well labelled plastic container and kept in a cool place in the chemistry laboratory at Kyambogo University. In this way, the crude plant materials can last for a long time without being degraded by the environment. The plants were identified by Dr. Hafishamana David at the Forestry Research Institute, Nakawa in Kampala Industrial Area.

\section{Extract preparation}

Crude bark extracts from A. coriaria, M. lucida, S. cordatum and V. paradoxa selected plants were prepared by adding $10 \mathrm{~g}$ of the dry and pulverized materials to $250 \mathrm{ml}$ of distilled water in a $400 \mathrm{ml}$ pyrex beaker. The mixture was stirred, heated and maintained and boiled for $2 \mathrm{~h}$, allowed to stand for $20 \mathrm{~min}$ and then filtered. The coloured filtrate $(200 \mathrm{ml})$ was used for dyeing cotton pieces of fabric in the presence of $10 \%$ (o.w.f) selected mordant.

\section{Dyeing process}

Dyeing of cotton fabrics ( $1.40 \mathrm{~g}$ each) was carried out using the simultaneous mordanting method at boiling for $1 \mathrm{~h}$ with constant stirring using a fixed amount of liquor ratio (1:200). Dyed samples were thoroughly washed with cold and hot water to remove any unfixed dyed material and finally dried in open air.

\section{Colour measurement and characterization}

Colour shades developed during the dyeing of the cotton fabrics were characterized from reflectance measurements using the Datacolour SF 600 spectra Flash reflectance spectrophotometer. The colour values of the dyed fabrics with selected mordants were obtained in terms of ClELab coordinates with illuminant $D_{65}$ with a 10 standard observer. The colour yield $(\mathrm{K} / \mathrm{S})$ values with selected mordants were calculated from reflectance measurements using the Kubelka-Munk equation. The amount of light reflected at each wavelength by each dyed fabric sample was plotted as a percentage of the amount of light falling on the coloured surface at each wavelength. The curves thus obtained provided a detailed description of the colour properties of each dyed sample. Colour fastness properties of dyed samples with mordant were evaluated using standard procedures. Light fastness was evaluated by exposing dyed fabric samples to direct sunlight alongside standard blue woolen fabrics for 30 days with a maximum temperature of $26^{\circ} \mathrm{C}$.

\section{RESULTS}

Natural dyes mostly require a mordant to be fixed onto the textile fibre (Jothi, 2008). Common mordants like alum, potassium dichromate, stannous chloride and ferrous sulphate were used in this study. They had affinity for the dye and the cotton fibers resulting to strong complexes with the dye inside the fibre matrix. The shades of colour developed on the cotton fabrics from the crude dye materials are shown in Figures 1 to 4 were yellow and brown indicate the major involvement of flavonoid and tannin colour moieties during the dyeing process. The results 


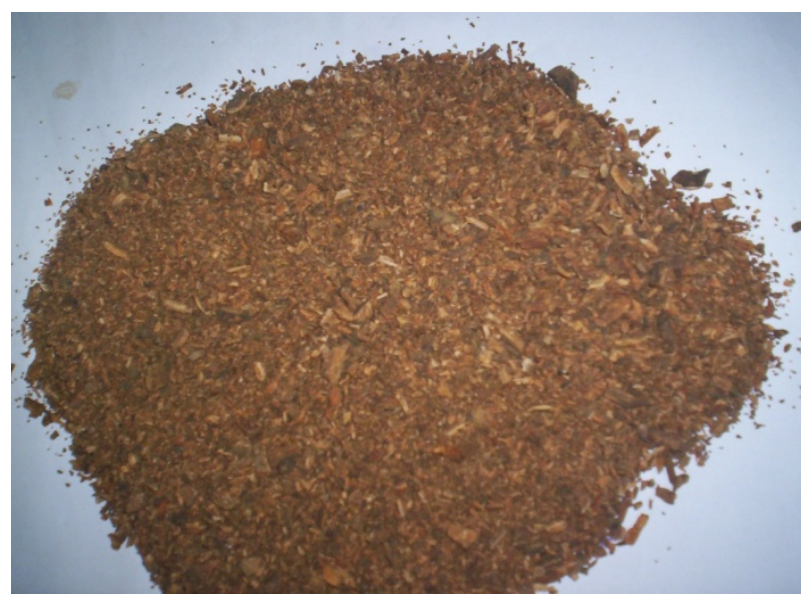

Figure 2. Morinda lucida crude bark material.

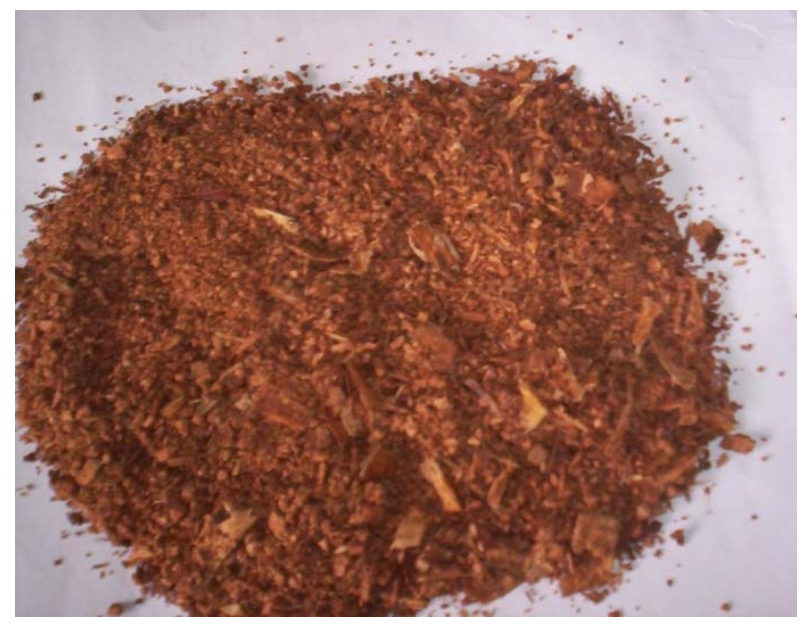

Figure 3. Syzygium cordatum crude bark material.

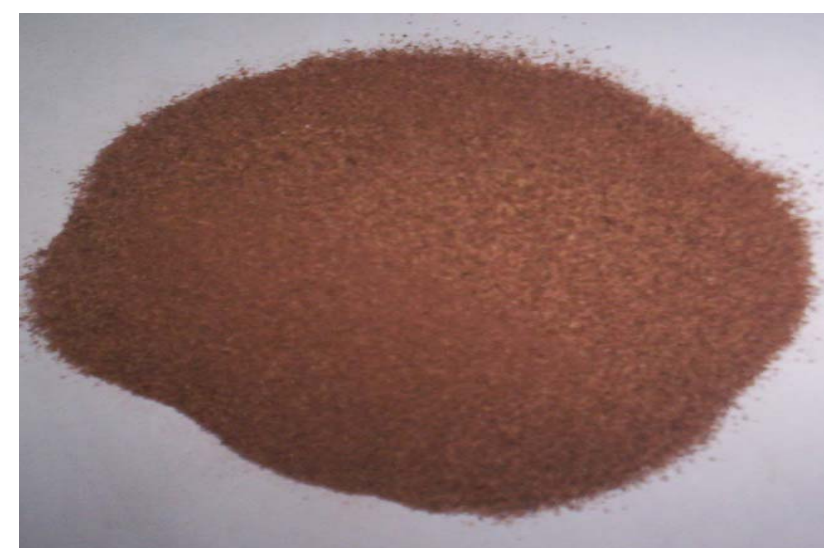

Figure 4. Vitellaria paradoxa crude bark material.

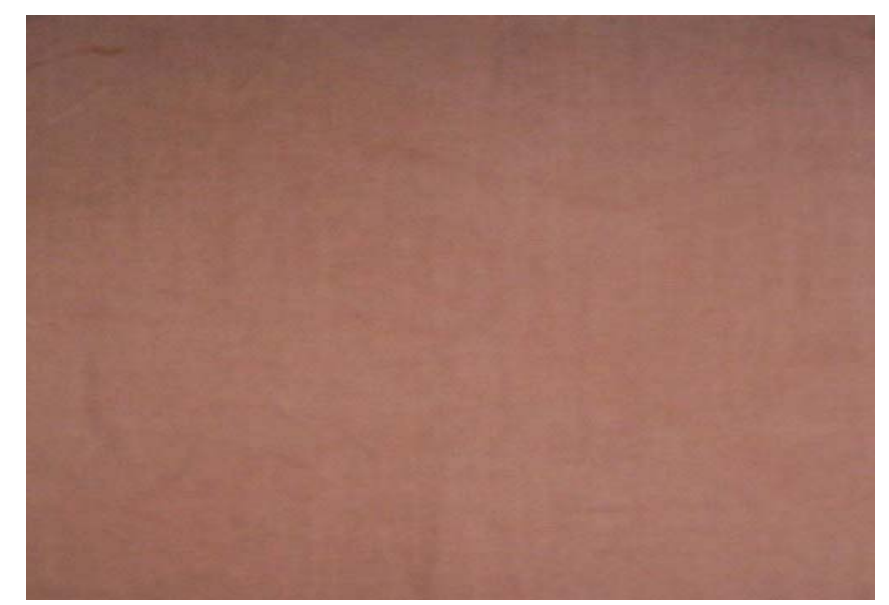

Figure 5. Cotton fabric dyed with Albizia coriaria crude bark extract.

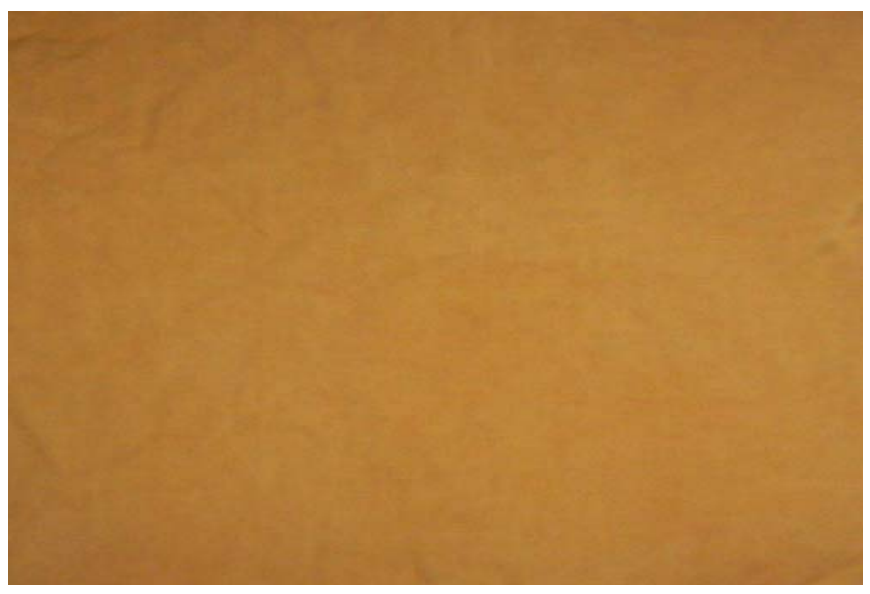

Figure 6. Cotton fabric dyed with Morinda lucida crude bark extract.

are shown in Figures 5 to 8 . The wash fastness of dye is influenced by the rate of diffusion of dye and state of dye inside the fibre. The dyes extracted from $A$. coriaria, $V$. paradoxa and $S$. cordatum exhibited good light and wash fastness. The presence of mordant improved the colour fastness and dyeability of the dyes by enhancing interactions between the dyes and cotton fibres. The poor wash fastness for $M$. lucida could be attributed to the presence of smaller dye-metal complexes and weaker dye-fibre interactions as compared to the other natural dyes, thus making them easier to wash out or diffuse from the fibre. This confirms the report that the majority of yellow dyes have poor to light and wash fastness properties (Tim and 


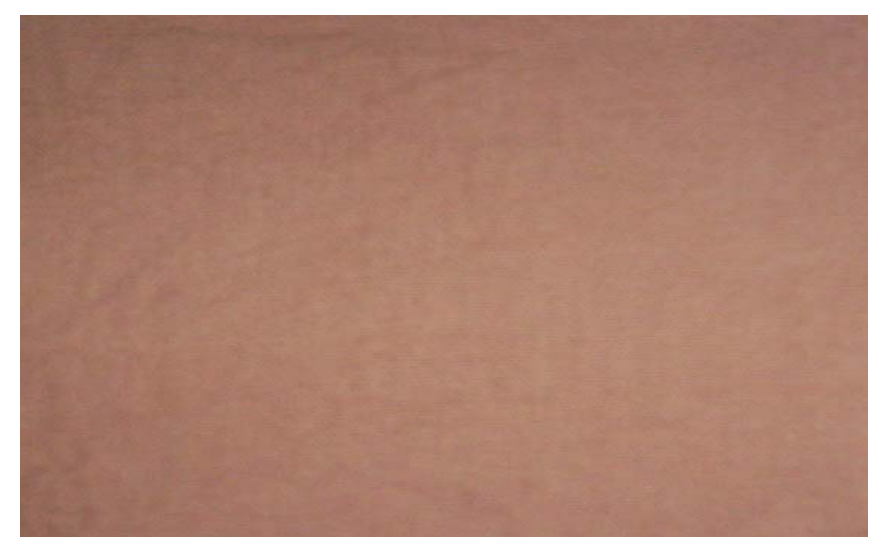

Figure 7. Cotton fabric dyed with Syzygium cordatum bark crude extract.

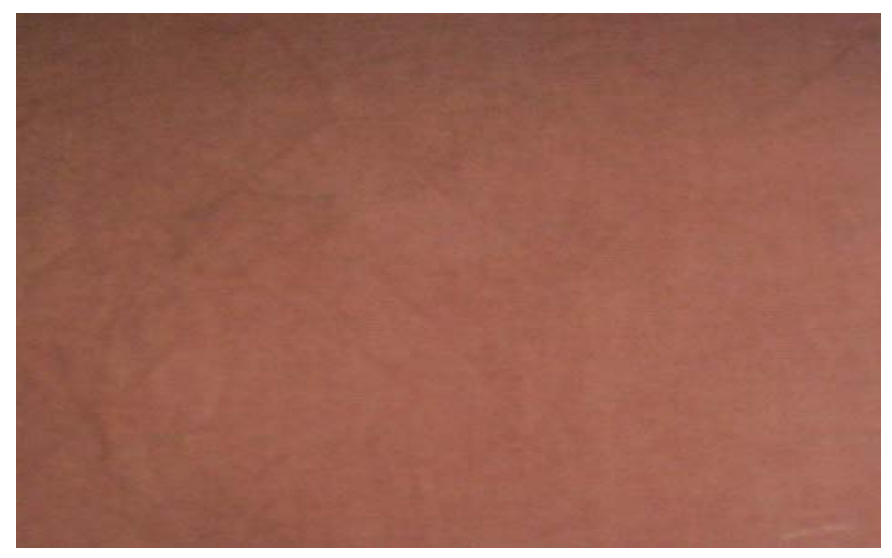

Figure 8. Cotton fabric dyed with Vitellaria paradoxa crude bark extract.

Sheila, 1966). The results of colour fastness to light and washing are shown in Table 1. It is possible that the presence of tannin moieties in the crude extracts of $A$. coriaria, S. cordatum and V. paradoxa enhance their colour fastness by introducing additional hydroxyl and carboxyl functional groups for coordination and stronger dyefibre-mordant complex formation within the fibre matrix (Wanyama et al., 2011; Ashis and Agarwal, 2009). The effect of selected mordants on colour fastness and dyeability of the cotton material highlights the significant role mordants play in colour characterization of naturally dyed fabric materials. The hue, chroma and light fastness of dyed fabric samples were affected depending on the phenolic composition of the crude plant extracts in this study. The results are shown in Tables 2, 3, 4, 5 and 6 . The hue values $(\mathrm{H})$ for each plant sample correlate with the phenolic chemical composition of the crude plant extracts and is mordant dependent.

\section{DISCUSSION}

The hues for all the crude plant extracts in this study were from yellowish to red and lying in the first quadrant of the colour space diagram. The amount of light reflecting from each coloured surface was plotted against the amount of light falling on the surface of the dyed fabric samples resulting in characteristic spectral reflectance curves shown in Figures 9 to 13. They represent a permanent record of the reflectance characteristics of the coloured fabric surfaces and vary from plant to plant. The substantivity of the colour components is also represented by the nature of the spectral reflectance curves. Higher substantivity is characterized by low values of reflectance. The values of lightness $(\mathrm{L})$ were very high for all the dyed fabric samples. The values of chroma (C) were low meaning that the dyed fabric materials were all not rich in colour. The colour absorption property of all the dyed fabric samples showed the yellow-red shade range in the visible range of color between $400-480 \mathrm{~nm}$. Potassium aluminium sulphate and stannous chloride mordants exhibited the highest $\mathrm{K} / \mathrm{S}$ values with $A$. coriaria crude extract (Figure 14); potassium aluminium sulphate and ferrous sulphate exhibited the highest K/S values with $M$. lucida bark and root extracts (Figures 15 and 16), ferrous sulphate, alum and potassium dichromate exhibited the highest K/S values with S. cordatum (Figure 17) while stannous chloride and potassium aluminium sulphate (alum) exhibited the highest K/S values with $V$. paradoxa (Figure 18) due to the ability to form strong coordination complexes with the dye molecules. This strong coordination tendency of the mordants in each case enhanced the interaction between the cotton fibres and the dyes, resulting in high dye uptake.

\section{Conclusions}

From the results obtained, it could be concluded that natural dyes extracted from $A$. coriaria (bark), M. lucida (bark and roots), S. cordatum (bark) and V. paradoxa (bark) selected dye-yielding plants are of textile importance. The colourfastness properties of the natural dyes investigated indicated potential use in the textile industry. The use of different mordants showed the effectiveness of dye fixation by metal complexation. The specific objectives of the present work were to extract the dyes, characterize them and use them to dye cotton fabrics and the results show 
Table 1. Light and washing fastness of selected dye-yielding plants in Uganda.

\begin{tabular}{llccc}
\hline \multirow{2}{*}{ Local name } & Botanical name & Part used & \multicolumn{2}{c}{ Colour fastness to: } \\
\cline { 4 - 5 } & Albizia coriaria & Bark & Light & Washing \\
\hline Mugavu & Morinda lucida & Bark & $3-4$ & $3-4$ \\
Mubajansali & Syzygium cordatum & Bark & $3-4$ & $2-3$ \\
Kanziroziro & Vitellaria paradoxa & bark & $3-4$ & $4-5$ \\
Nakunguli & & & & $4-5$ \\
\hline
\end{tabular}

Table 2. Effect of selected mordants on colour of cotton sample dyed with Albizia coriaria crude bark extract.

\begin{tabular}{lccccc}
\hline \multirow{2}{*}{ Mordant used } & \multicolumn{5}{c}{ Colour coordinates } \\
\cline { 2 - 6 } & L & a & b & C & H \\
\hline Potassium aluminium sulphate & 69.05 & 3.35 & 37.92 & 38.07 & 84.96 \\
Ferrous sulphate & 57.55 & 2.08 & 17.65 & 17.77 & 83.27 \\
Stannous chloride & 68.42 & 4.35 & 31.33 & 31.63 & 82.89 \\
Potassium dichromate & 67.73 & 2.84 & 30.19 & 30.33 & 84.62 \\
\hline
\end{tabular}

Table 3. Effect of selected mordants on colour of cotton sample dyed with Morinda lucida crude root extract.

\begin{tabular}{lccccc}
\hline \multirow{2}{*}{ Mordant used } & \multicolumn{5}{c}{ Colour coordinates } \\
\cline { 2 - 6 } & $\mathbf{L}$ & $\mathbf{a}$ & $\mathbf{b}$ & $\mathbf{C}$ & $\mathbf{H}$ \\
\hline Potassium aluminium sulphate & 58.57 & 13.26 & 21.28 & 25.70 & 58.08 \\
Ferrous sulphate & 21.47 & 5.92 & 6.46 & 8.76 & 47.13 \\
Stannous chloride & 63.98 & 12.05 & 14.69 & 19.00 & 50.63 \\
Potassium dichromate & 68.59 & 8.22 & 11.88 & 14.45 & 55.31 \\
\hline
\end{tabular}

Table 4. Effect of selected mordants on colour of cotton sample dyed with Morinda lucida crude bark extract.

\begin{tabular}{lccccc}
\hline \multirow{2}{*}{ Mordant used } & \multicolumn{5}{c}{ Colour coordinates } \\
\cline { 2 - 6 } & $\mathbf{L}$ & $\mathbf{a}$ & $\mathbf{b}$ & $\mathbf{C}$ & $\mathbf{H}$ \\
\hline Potassium aluminium sulphate & 76.24 & -0.77 & 37.52 & 37.52 & 91.17 \\
Ferrous sulphate & 70.39 & 3.58 & 8.59 & 9.31 & 67.38 \\
Stannous chloride & 80.94 & -1.59 & 14.63 & 14.72 & 96.21 \\
Potassium dichromate & 75.81 & 2.68 & 11.83 & 12.13 & 77.24 \\
\hline
\end{tabular}

Table 5. Effect of selected mordants on colour of cotton sample dyed sample with Syzygium cordatum crude bark extract.

\begin{tabular}{lccccc}
\hline \multirow{2}{*}{ Mordant used } & \multicolumn{5}{c}{ Colour coordinates } \\
\cline { 2 - 6 } & $\mathbf{L}$ & $\mathbf{a}$ & $\mathbf{b}$ & $\mathbf{C}$ & $\mathbf{H}$ \\
\hline Potassium aluminium sulphate & 60.13 & 8.29 & 14.72 & 16.89 & 60.62 \\
Ferrous sulphate & 50.39 & 5.93 & 11.34 & 12.80 & 62.42 \\
Stannous chloride & 61.52 & 9.40 & 11.81 & 15.10 & 51.50 \\
Potassium dichromate & 58.09 & 8.31 & 14.13 & 16.39 & 59.53 \\
\hline
\end{tabular}


Table 6. Effect of selected mordants on colour of cotton sample dyed with Vitellaria paradoxa crude bark extract.

\begin{tabular}{llllll}
\hline \multirow{2}{*}{ Mordant used } & \multicolumn{2}{l}{ Colour coordinates } & & & \\
\cline { 2 - 6 } & $\mathbf{L}$ & $\mathbf{a}$ & $\mathbf{b}$ & $\mathbf{C}$ & $\mathbf{H}$ \\
\hline Potassium aluminium sulphate & 59.43 & 13.27 & 19.16 & 23.31 & 55.31 \\
Ferrous sulphate & 63.75 & 3.86 & 7.96 & 8.85 & 64.11 \\
Stannous chloride & 58.96 & 9.36 & 12.21 & 15.38 & 52.54 \\
Potassium dichromate & 66.05 & 4.67 & 14.43 & 15.16 & 72.06 \\
\hline
\end{tabular}

\section{Change in $\mathrm{R}$ values with different mordants}

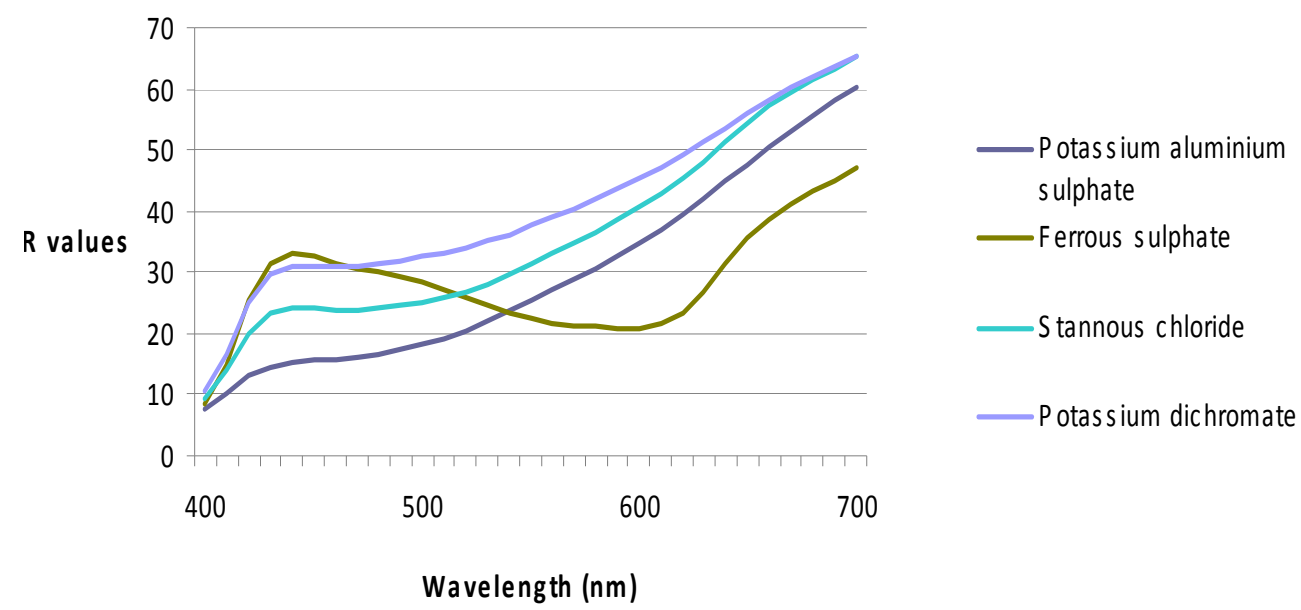

Figure 9. Change in reflectance with selected mordants for cotton fabrics dyed with Albizia coriaria crude bark extract.

\section{Change in $R$ values with different mordants}

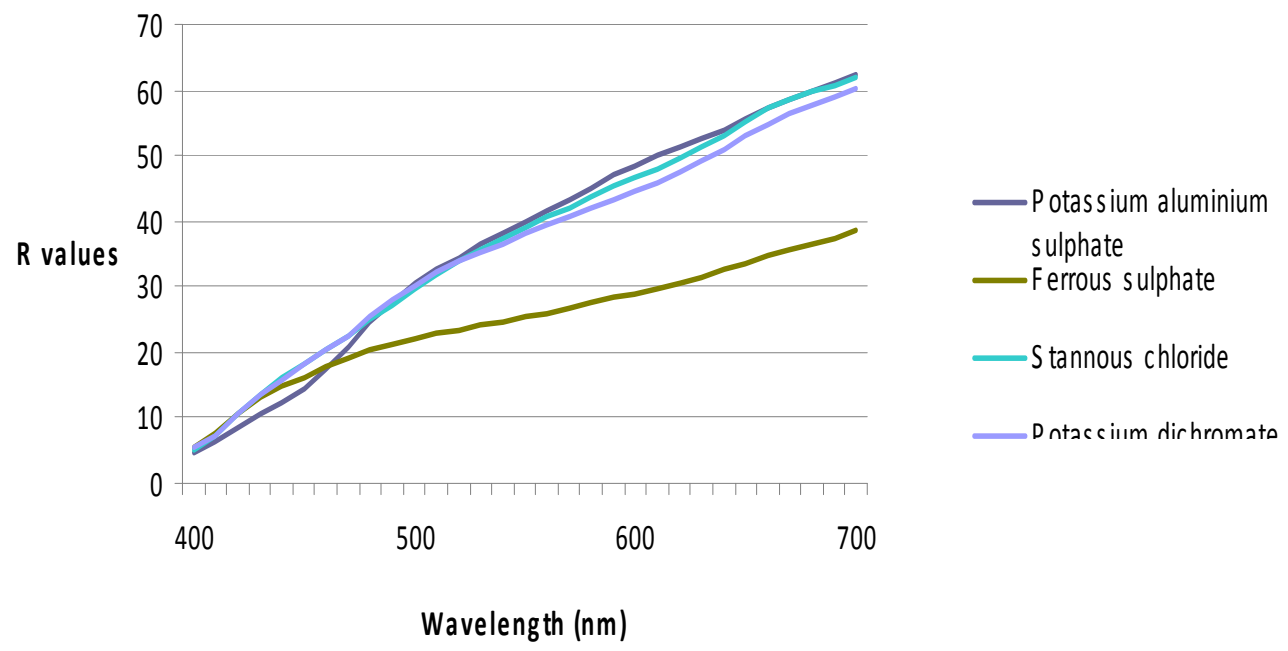

Figure 10. Change in reflectance with selected mordant for cotton fabrics dyed with Morinda lucida crude bark extract. 


\section{Change in $R$ values with different mordants}

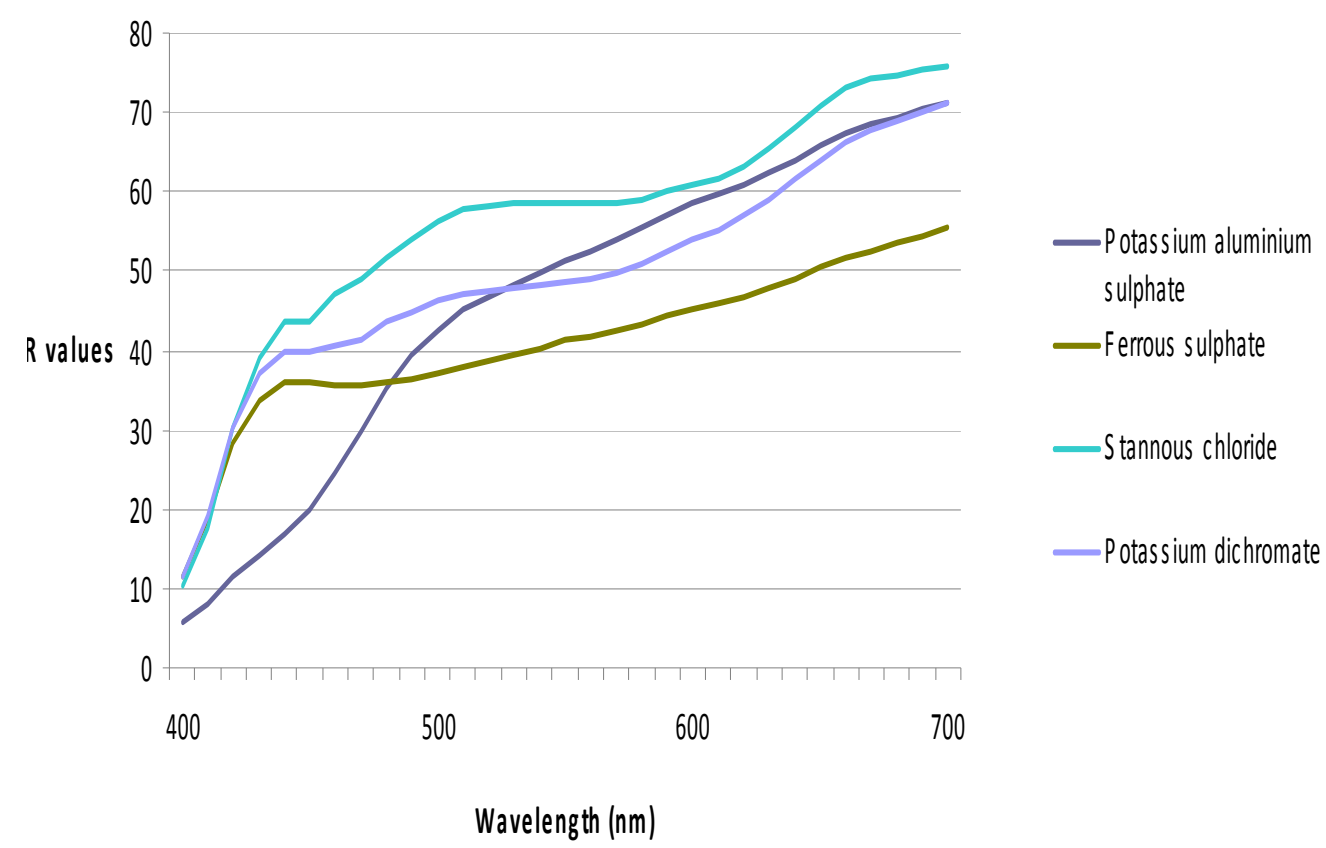

Figure 11. Change in reflectance with selected mordants for cotton fabrics dyed with Morinda lucida crude root extract.

\section{Change in $R$ values with different mordants}

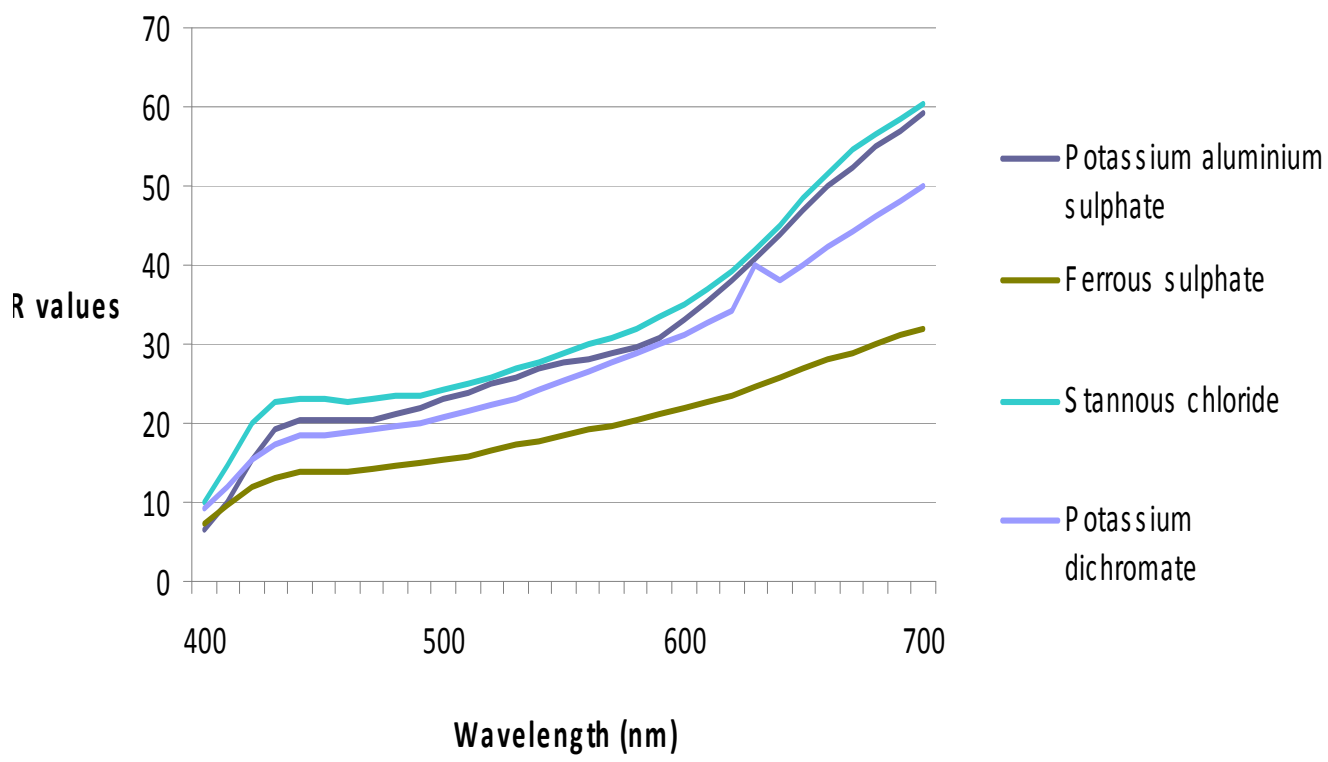

Figure 12. Change in reflectance with selected mordants for cotton fabrics dyed with Syzygium cordatum crude bark extract. 


\section{Change in $K / S$ values with different mordants}

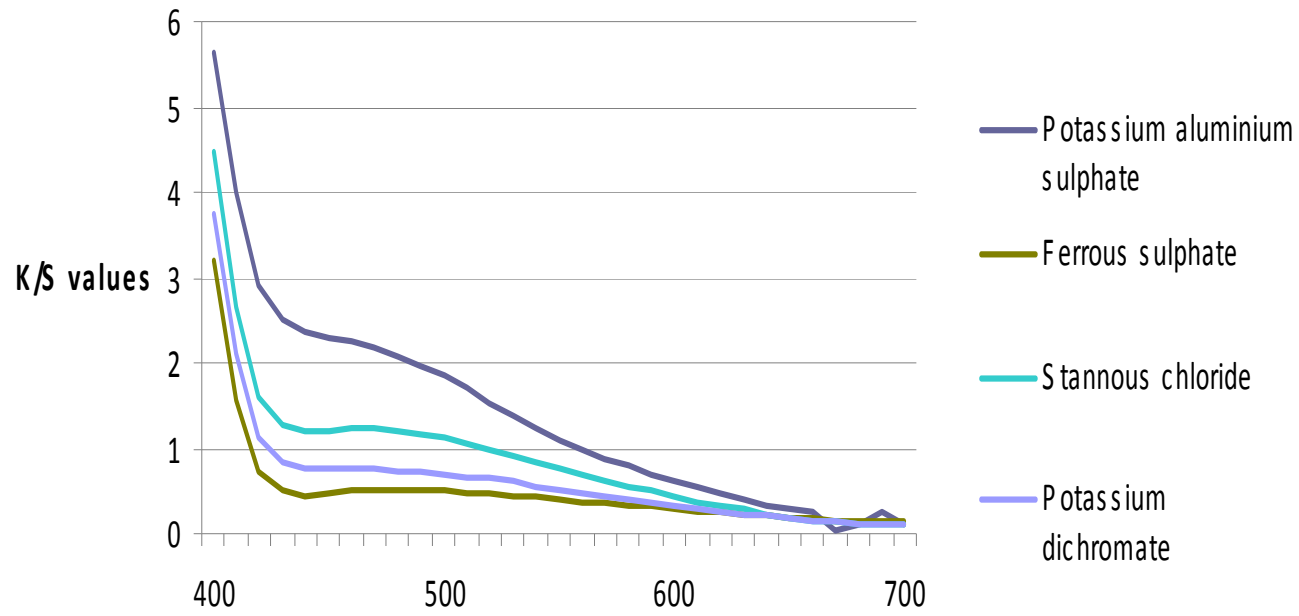

Wavelength $(\mathrm{nm})$

Figure 13. Change in reflectance with different mordants for cotton fabrics dyed with Vitellaria paradoxa crude bark extract.

\section{Change in $\mathrm{K} / \mathrm{S}$ values with different mordants}

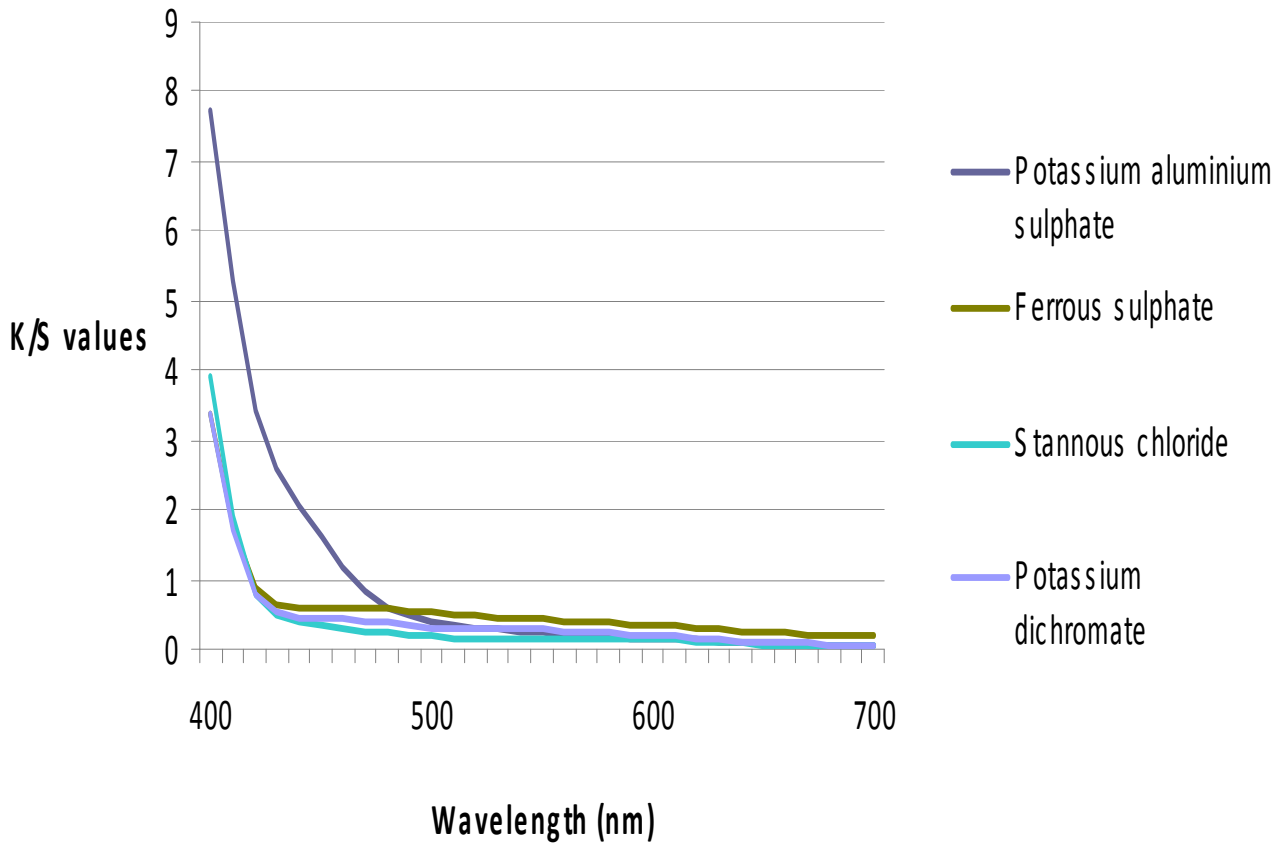

Figure 14. Change in $\mathrm{K} / \mathrm{S}$ with selected mordants for cotton fabrics dyed with Albizia coriaria crude bark extract. 


\section{Change in $K \$$ values with different mordants}

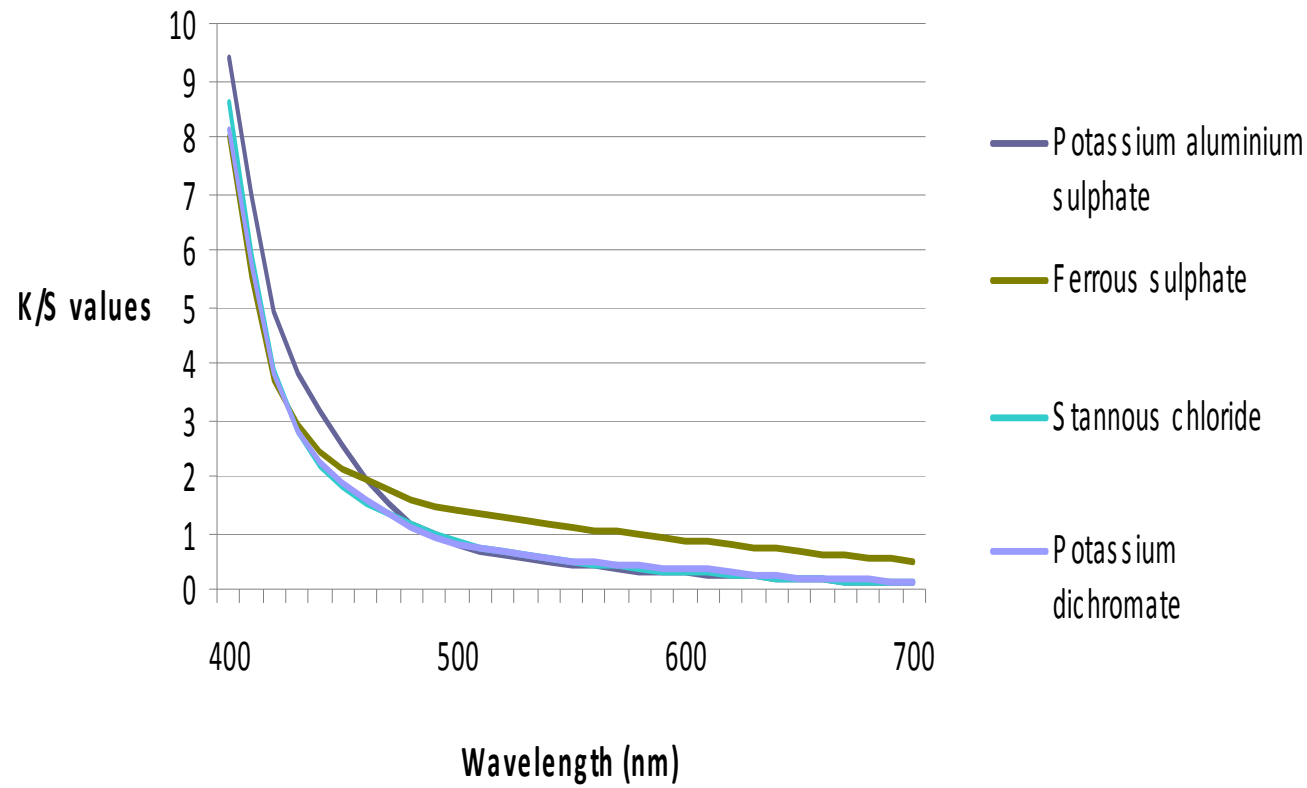

Figure 15. Change in K/S with selected mordants for cotton fabrics dyed with Morinda lucida root extract.

\section{Change in $\mathrm{K} / \mathrm{s}$ values with different mordants}

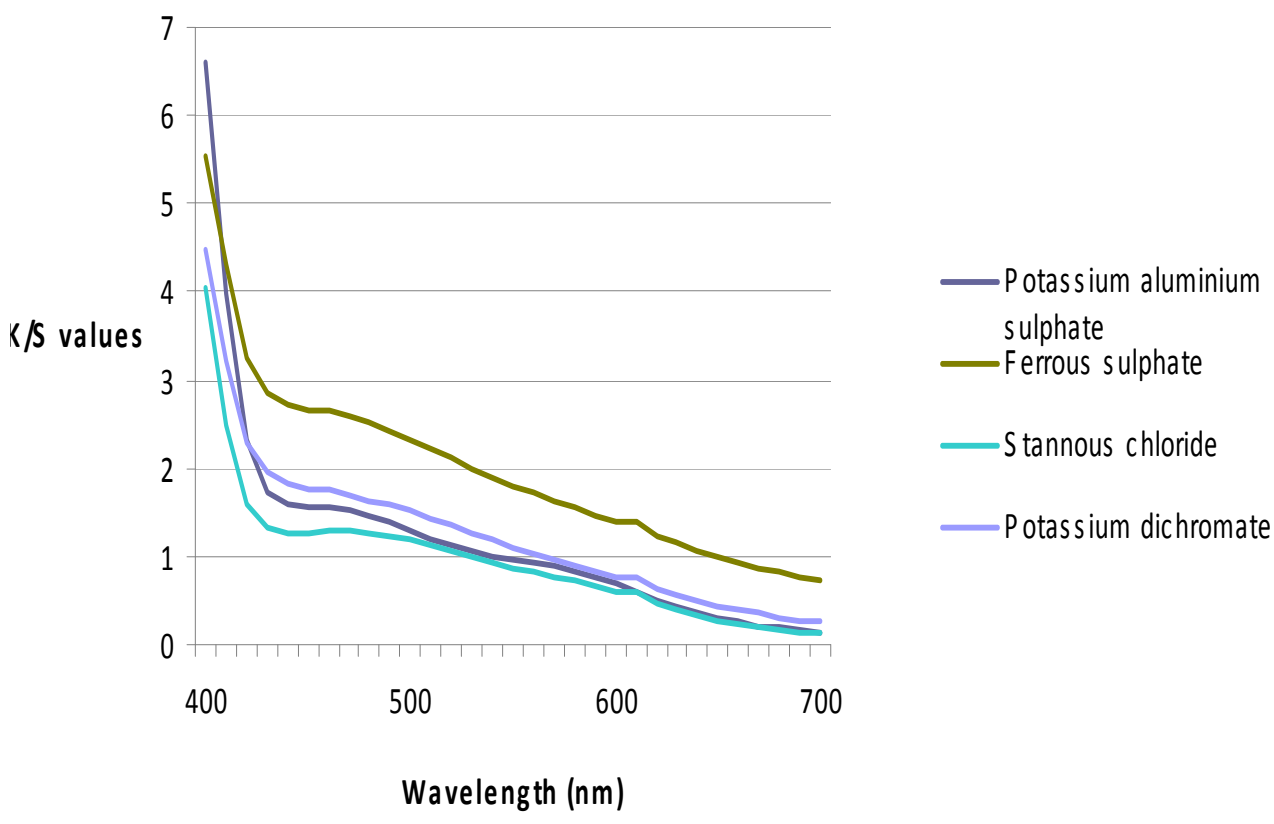

Figure 16. Change in K/S with selected mordants for cotton fabrics dyed with Morinda lucida bark extract. 


\section{Change in $R$ values with different mordants}

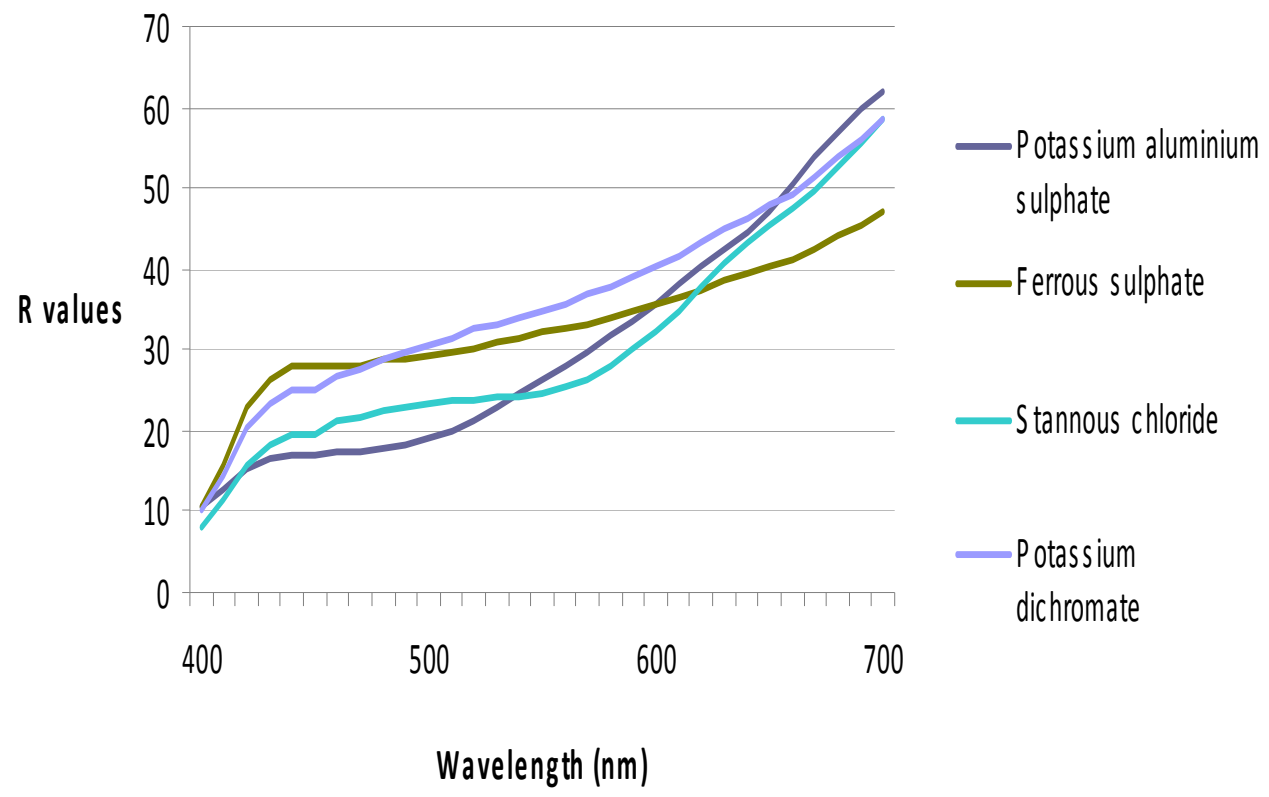

Figure 17. Change in K/S with selected mordants for cotton fabrics dyed with Syzygium cordatum crude bark extract.

\section{Chang e in $\mathrm{K} / \mathrm{S}$ values with different mordants}

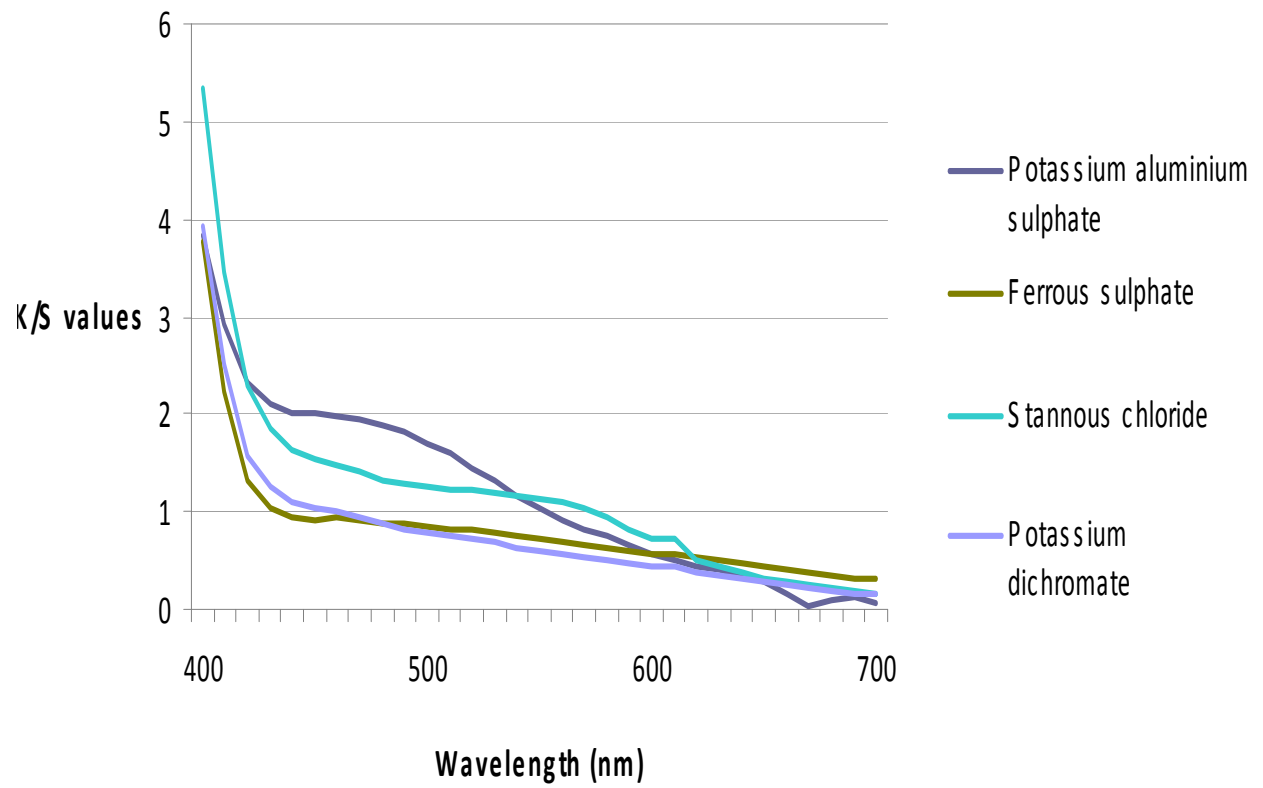

Figure 18. Change in $\mathrm{K} / \mathrm{S}$ with selected mordants for cotton fabrics with Vitellaria paradoxa crude bark extract. 
that the objectives were achieved. However, further work needs to be done to determine the chromophoric structures of the major colour components present in all the crude plant extracts that are responsible for the characteristic yellow and brown shades of colour developed on the cotton fabrics

\section{REFERENCES}

Ashis KS, Agarwal P (2009). Application of natural dyes on textiles. Indian J. Fibre Textile Res. 34:384-399.

Deo HT, Desai BK (1999). Dyeing of Cotton and Jute with tea as a natural dye. Colouration Technol. 115:7-8.

Gokhale SB, Tatiya AU, Bakliwal SR, Fursule RA (2004). Natural dyeyielding plants in India. Natural Product Radiance 3(4):228-234.

Samanta AK, Agarwal P (2009). Application of natural dyes on textiles. Review Article. Indian J. Fibre Text Res. 34:384-399.

Maria Z, Eleni N, Evangelia V, Eforia T (2010). Colour and fastness of natural dyes: revival of traditional dyeing techniques. Colouration Technol.127:18-27.

Ekrami E, Saberi M, Motlagh S, Mafi M (2011). Wool Dyeing using Rose Flower Petal. J. World Appl. Sci. 13(2):295-299.

Acguah SB, Oduro KA (2012). Traditional Cloth Dyeing Enterprise at Ntonso: challenges and Opportunities. West Afr. J. Appl. Ecol. 20(1):25-36.
Mayunga HHN (2007). Towards the discovery of drugs and pesticide agents from East Africa flora. The $12^{\text {th }}$ Napreca Symposium, July 2226, 2007, Hotel Africana, Uganda.

Jothi D (2008). Extraction of natural dyes from African marigold flower (Tegetes errecta) for textile colouration. Anvex Res. J. 8(2):49-53.

Tim P, Sheila L (1966). The Light fastness of natural dyes. Studies in conservation, 11(4):181-198.

Wanyama PAG, Kiremire BT, Murumu JES, Kamoga O (2011). Textile dyeing and phytochemical characterization of crude plant extracts derived from selected dye-yielding plants in Uganda. Int. J. Nat. Prod. Res. 1(2):26-31. 